\title{
Relationships between Tooth Eruption, Occlusion and Alveolar Bone Resorption: Histochemical and Cytological Studies of Bone Remodeling on Rat Incisor Alveolar Bone Facing the Enamel after Root Resection
}

\author{
Kazuharu IRIE and Hidehiro OzAw A \\ Department of Oral Anatomy, Niigata University School of Dentistry, Niigata, Japan
}

Received January 16, 1990

Summary. The labial side of rat incisor alveolar bone facing the enamel is continuously resorbed as the result of compressive force produced by the occlusion and eruption of incisors. In order to clarify the relationship between this mechanical compressive force and the bone cells involved in bone remodeling, we examined morphological changes occurring in the alveolar bone once the compressive force was eliminated by the removal of the proliferative odontogenic base (root resection according to BERKovITZ and THOMAS, 1969).

After root resection, the incisor migrated halfway along the socket. On the crestal part where incisor still existed, active osteoclasts were prominent on the bone surface, and flattened mononuclear cells lay close upon active osteoclasts. Sinusoidal blood vessels or capillaries were observed at short distances from the bone surface. On the basal part where socket was vacant, osteoblasts lined up on the newly formed bone, and the osteogenic cell layer lay on the osteoblasts. Between the two parts, which correspond to the reversal phase proposed by BARON (1977), osteoblastic cells with developed cell organelles increased in number and the distance between blood vessels and bone surface increased. Osteoclasts reduced their activities, and osteoblastic cells often wedged themselves between the osteoclasts and bone surface.

These findings indicate that the elimination of compressive force mediated by incisors leads to the activation of osteoblastic cells and inactivation of osteoclasts, which results in a conversion from bone resorption to bone formation. Thus, osteoblastic cells may play an important role in controlling osteoclastic activity in conversion from bone resorption to bone formation, partly by a direct effect and partly by controlling the access of blood vessels to the bone surface.
In our previous study on the rat incisor socket, we revealed that the alveolar bone is actively remodeled on the lingual side, while the bone is not newly formed but rather continuously resorbed on the labial side (OzAWA et al., 1989a; IRIE and OzAWA, 1990). Compressive force produced by occlusion and by the development/eruption of the incisor may cause this continuous resorption. We have also demonstrated that the osteoblastic cells are located close to the

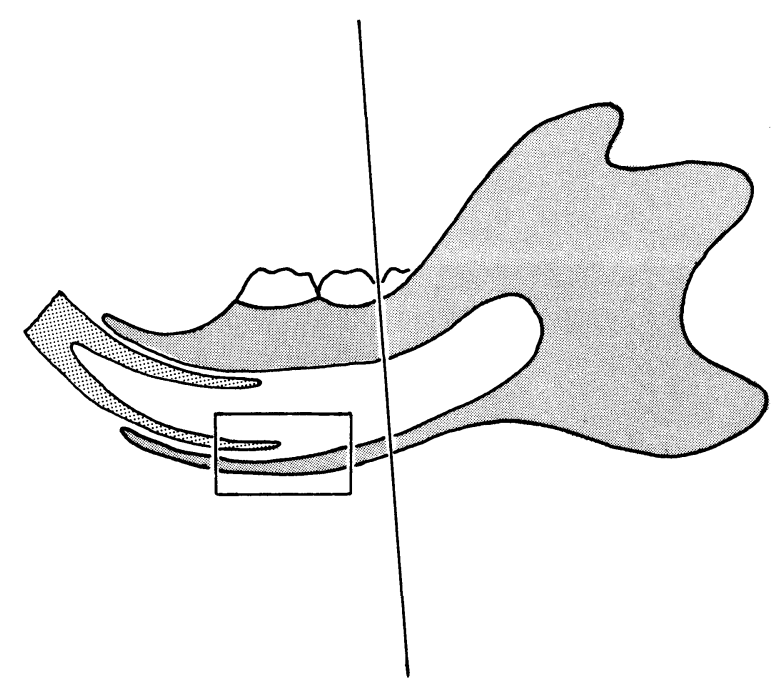

Fig. 1. Schema of mandibles used in this study. The boxed part was used in the morphological study. The line on the right of the figure indicates the plane observed in the chronological study. 
osteoclasts on the bone surface where the bone is resorbed continuously (OzAWA et al., 1989a), which supports the idea of osteoblastic cells influencing the differentiation and/or activation of osteoclasts as suggested by many investigators (BARON et al., 1980; EJIRI, 1983; BURGER et al., 1984; TAKAHASHI et al., 1988). Several reports exist on histological studies of bone resorption induced by extrinsic compressive force in such cases as orthodontic treatment (SCHWARZ, 1932; ZAKI and VAN HUYSEN, 1963; AZUMA, 1970; RYGH, 1972, 1973; KURIHARA, 1977; KURIHARA and ENLOW, 1980), but only a few reports dealing with histological changes after the elimination of physiological compressive force, especially concerning cellular events involved in bone remodeling, are available at this date.

BERKOVITZ and THOMAS (1969) reported that incisor kept erupting after removal of the proliferative odontogenic base (i.e., root resection), and left a vacant socket behind the incisor base. Therefore, compressive force mediated by incisor was considered to be absent. This study aims to demonstrate the histological changes occuring on the rat incisor alveolar bone facing the enamel after the elimination of compressive force as accomplished by root resection,

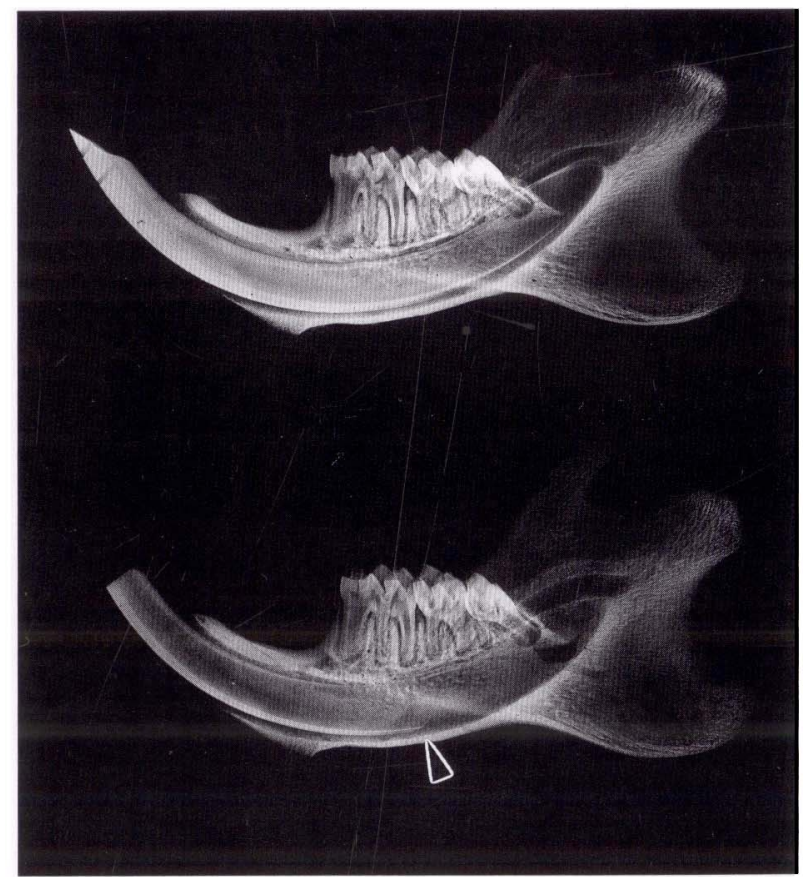

Fig. 2. Radiograph of the mandibles. Upper: untreated control. Lower: root resection. The arrowhead indicates the base of the incisor. and seeks to clarify the relationship between mechanical force, especially the compressive force, and the bone cells involved in bone remodeling.

\section{MATERIALS AND METHODS}

The mandibles of Wistar strain rats about $200 \mathrm{~g}$ in weight were used. Removal of incisors was performed by root resection according to BERKOVITZ and Thomas (1969). After shaving the left cheek, a horizontal incision was made along a plane passing through the angle of the mouth and external auditory
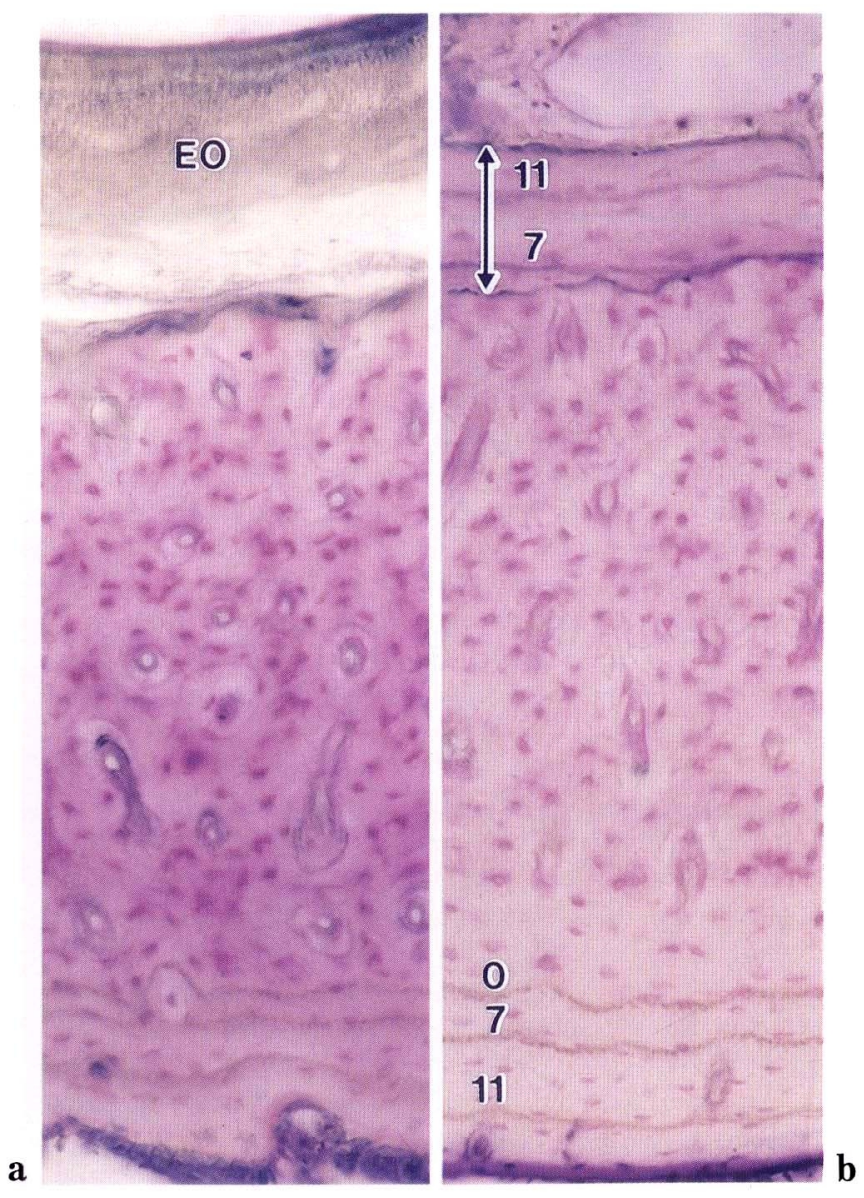

Fig. 3. Distal cross section of a second molar indicating lead labeling in the labial alveolar bone. a. Untreated control. EO enamel organ. b. Root resection. Note the bone apposition on the inner surface of the root-resected rat (b, arrows), while the label is absent in untreated controls (a). The numbers indicate the day EDTA-Pb was injected. a, b: $\times 150$ 

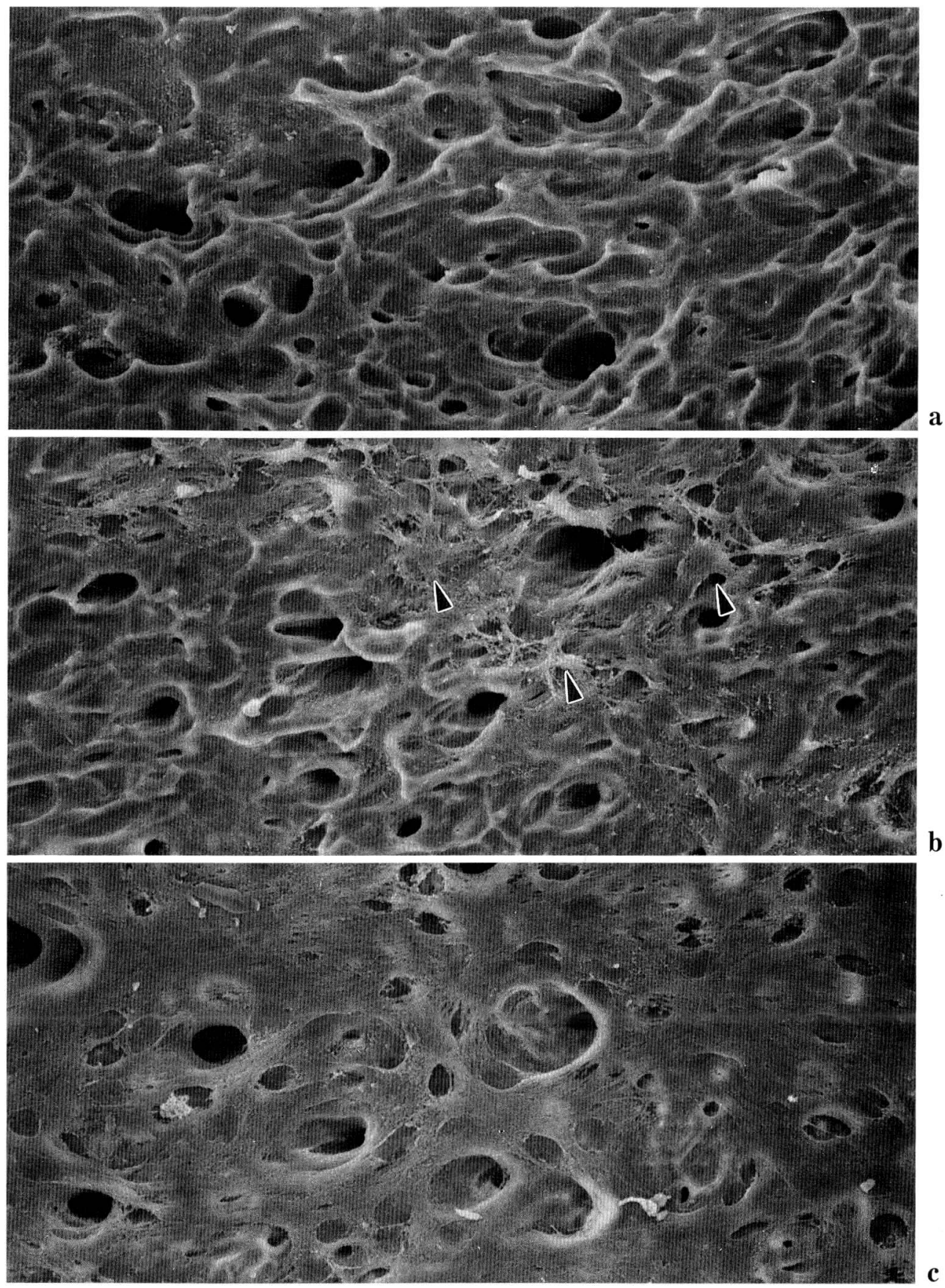

Fig. 4. SEM images of the alveolar bone surface facing the enamel. a. Shallow resorptive lacunae in the crestal part. b. Transitional part. Fibrous structures (arrowheads) indicate new bone formation. c. Basal part. Newly formed osteocytic lacunae are scattered on the bone formation surface. a-c: $\times 450$ 
meatus. The skin was reflected and further incision was made on the masseter. After reflection of the masseter, the proliferative odontogenic base was destroyed with a round bur. The incisor was trimmed every other day for 2 weeks to prevent it from occlusion.

\section{Chronological labeling}

Lead-labeling technique was performed according to OKADA and MimURA (1938). EDTA-Pb (30 mg/kg) was injected intraperitoneally, $3 \mathrm{~h}$ before root resection, at 7 and 11 days after root resection and $3 \mathrm{~h}$ before sacrifice. Following intracardiac perfusion with $10 \%$ formaline in a $0.1 \mathrm{M}$ phosphate buffer $(\mathrm{pH}$

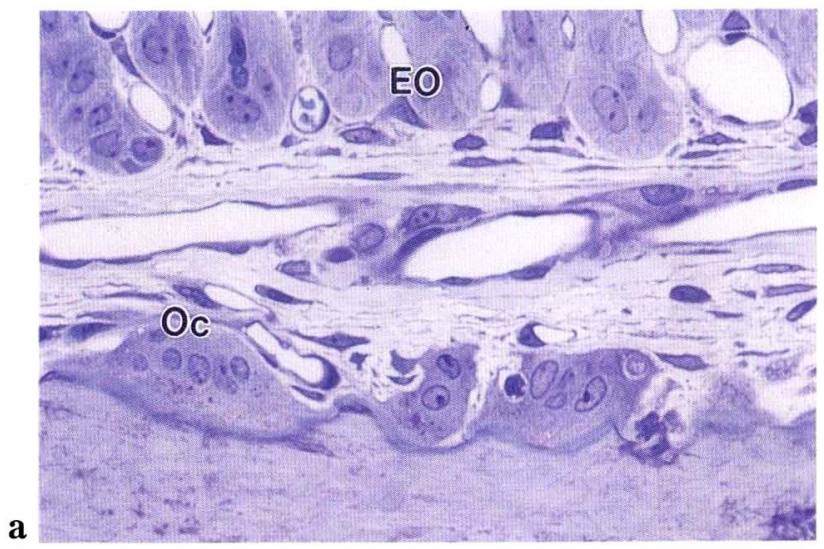

b
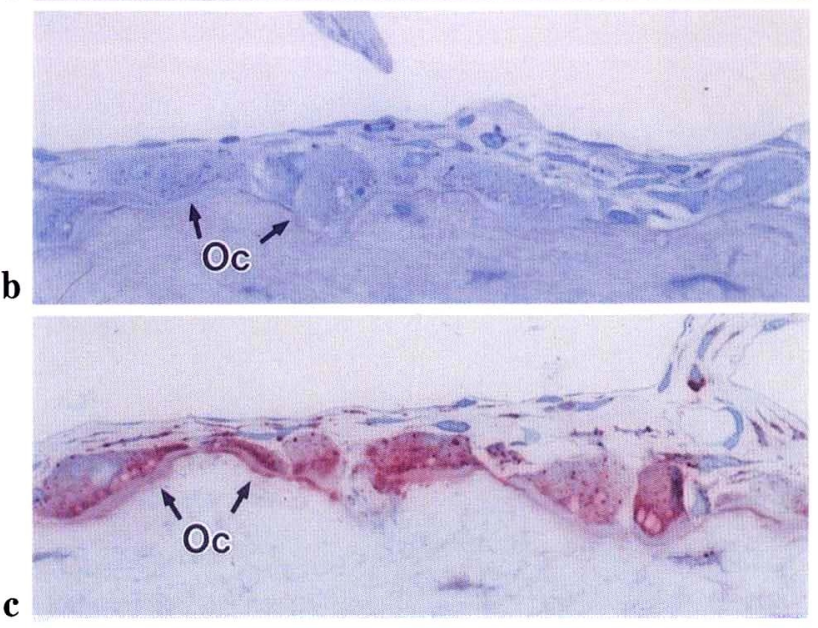

Fig. 5 a-c. Light micrographs of the bone surface on the crestal part. Osteoclasts $(O c)$ are prominent on the bone surface facing the incisor. Note intense ACPase activity in the osteoclast and little PAS reaction in mononuclear cells. EO enamel ergan. a: Toluidine blue $(T B), \times 600$; b: PAS, $\times 500$; c: ACPase, $\times 500$
7.4), the mandibles were removed and immersed in the same fixative for one night. They were decalcified in $0.2 \mathrm{~N}$ hydrochloride with saturated hydrogen sulfide for one week and dissected. The specimens were embedded in gelatine and cross sections distal to the second molar (Fig. 1) of about $30 \mu \mathrm{m}$ thick were obtained using a cryostat (IEC, Minotome). The samples were immersed in $0.1 \%$ gold chloride and stained with toluidine blue and observed.

\section{Preparation for morphological studies}

Following intracardiac perfusion with $2.5 \%$ glutaraldehyde, $2.0 \%$ paraformaldehyde mixture in a $0.065 \mathrm{M}$ cacodylate buffer ( $\mathrm{pH} 7.4$ ) containing $0.05 \%$ calcium

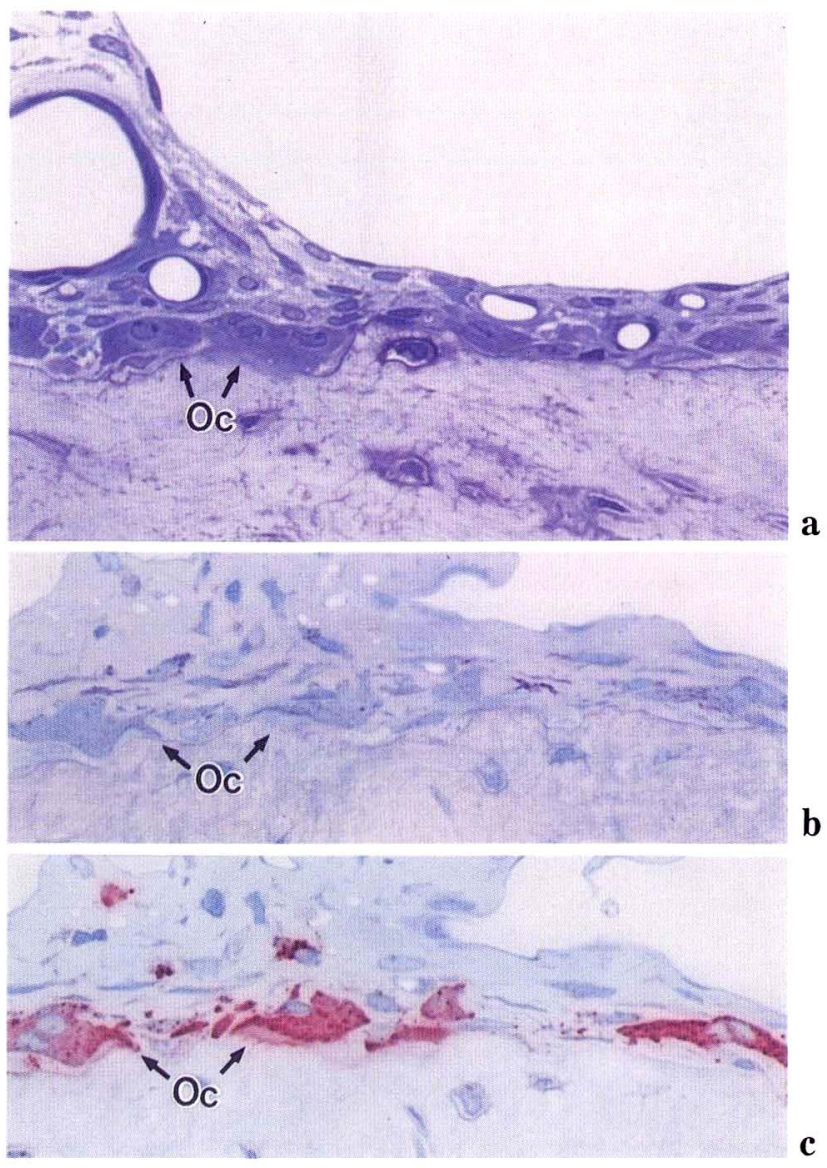

Fig. 6 a-c. Crestal half of the transitional part. Osteoclasts $(O c)$ are still prominent on the surface, but reduced in size and number. PAS positive granules in mononuclear cells are enriched. Note the increased distance between the blood vessels and bone surface. a: TB, $\times 600$; b: PAS, $\times 500$; c: ACPase, $\times 500$ 
chloride, the mandibles were removed and immersed in the same fixative for one and a half hours. Radiographs were taken (Softex) to determine the exact location of the incisor base. The region of the mandibles used for morphological study is indicated in Figure 1.

\section{Scanning electron microscopic study of the bone surface}

After the radiograph taken, the labial alveolar bone was cut using a dental engine, then removed. The bone segment was immersed in 5\% sodium hypochloride for $1 \mathrm{~min}$ to remove organic materials and washed with distilled water. The specimen was postfixed with $1 \%$ osmium tetroxide, dehydrated, critical point-dried and coated with gold using an ion-coater (Eiko, IB-3), and observed by SEM (Hitachi S-570).

\section{Histochemical studies}

$P A S$ reaction and acid phosphatase (ACPase) activity: The mandibles were decalcified by $5 \%$ EDTA for 3 weeks at $4^{\circ} \mathrm{C}$. Following dissection, the specimens were dehydrated and embedded in Technovit 7100 . Semithin sections were prepared for PAS reaction and detection of ACPase activity. PAS reaction was performed by the procedure according to MCMANUS (1948). The sections for ACPase activity were in-

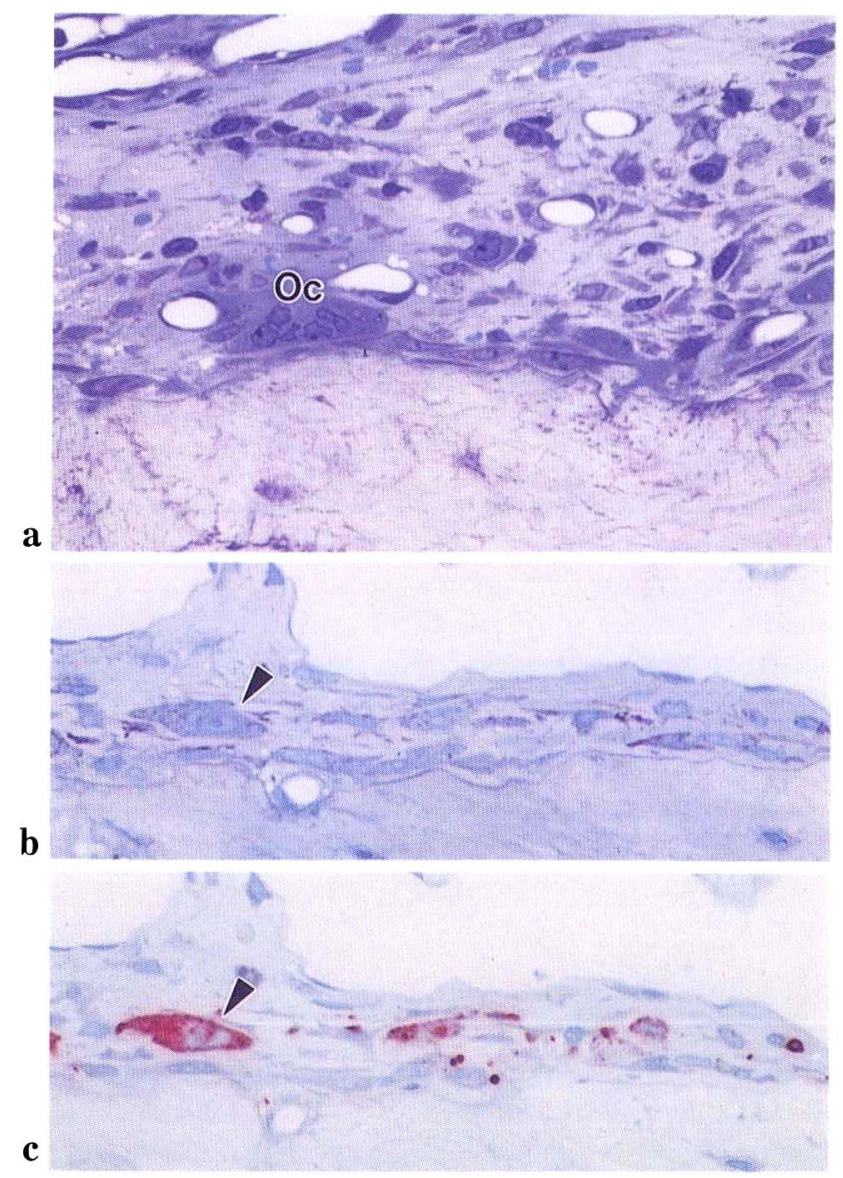

Fig. 7 a-c. Basal half of the transitional part. Mononulear cells are prominent on the surface. Arrowheads indicate detached osteoclasts. $O c$ osteoclast. a: TB, $\times 600$; b: PAS, $\times 500$; c: ACPase, $\times 500$

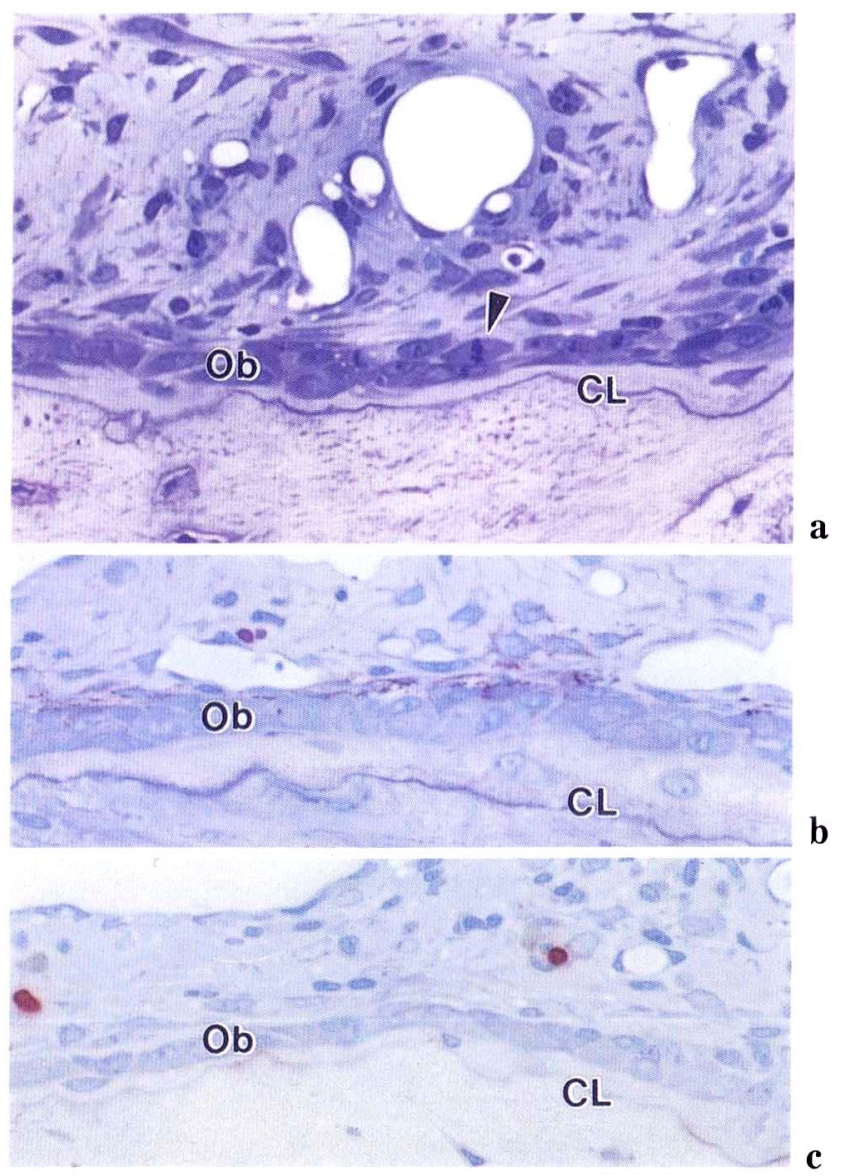

Fig. 8 a-c. Basal part. Osteoblasts $(O b)$ lined up on newly formed bone. Note the intense reaction of PAS in the osteogenic cell layer behind osteoblasts $(\mathrm{Ob})$. Arrowhead indicates mitosis. CL cement line. a: TB, $\times 600$; b: PAS, $\times 500$; c: ACPase, $\times 500$ 
cubated in the medium according to the procedure by BuRstone (1958) using naphthol AS-BI phosphate as a substrate. Incubation was carried out at $37^{\circ} \mathrm{C}$ for $3 \mathrm{~h}$.

Alkaline phosphatase (ALPase) activity: The mandibles were decalcified by 5\% EDTA for 3 weeks at $4^{\circ} \mathrm{C}$. The specimens were embedded in Tissue-Tek and $10 \mu \mathrm{m}$ cryostat sections were prepared. The sections were incubated in the medium according to the procedure by BURSTONE (1962) using naphthol AS-MX phosphate as a substrate. Incubation was carried out at $37^{\circ} \mathrm{C}$ for $30 \mathrm{~min}$.

\section{Electron microscopic study}

The mandibles were decalcified with 5\% EDTA for 3 weeks as $4^{\circ} \mathrm{C}$ and dissected. Following postfixation in $1 \%$ osmium tetroxide (some contained 1.5\% potassium ferrocyanide), specimens were dehydrated
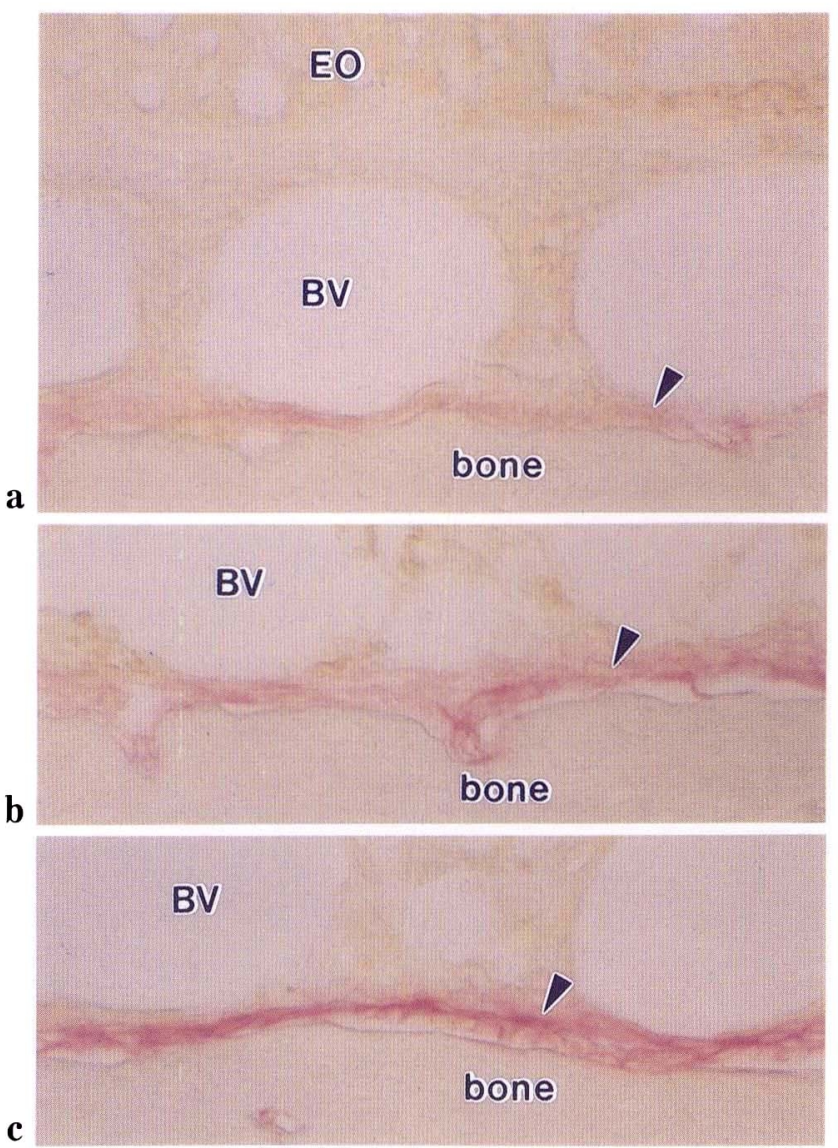

Fig. 9. Light micrograph of ALPase activity (arrowheads). a. Crestal part. b. Transitional part. c. An intense activity is detected in the basal part. $B V$ blood vessel, $E O$ enamel organ. a-c: $\times 250$ and embedded in Epon 812. Ultrathin sections were obtained and stained with uranyl acetate and lead citrate and observed by TEM (Hitachi H-500).

\section{RESULTS}

\section{Radiographic findings}

After root resection, the incisor continued to erupt and the base of the tooth moved halfway along the tooth socket. The incisor socket was divided into two distinct parts according to the existence of the incisor: the crestal part where the incisor remained, and the basal part where the socket was vacant (Fig. 2).

\section{Chronological labeling}

Lead labeling demonstrated the bone apposition on both the inside and outside of the labial alveolar bone in root-resected rats. In untreated control rats, labeling lines were absent from the inner bone matrix facing the enamel (Fig. 3).

\section{SEM observations of the bone surface}

The bone surface was divided into three distinct areas. In the area of the crestal part of the alveolar bone, shallow resorptive lacunae were prominent (Fig. 4a), while in the area of basal part, oval cavities corresponding to young osteocyte lacunae were scattered over the smooth bone forming surface (Fig. 4c). Between the above two areas, hereafter referred to as the transitional area, several characteristic features of both bone resorption and bone formation were visible (Fig. 4b).

\section{Histological and histochemical observations}

Three distinct parts, i.e., crestal, basal, and transitional, were observed as in the SEM observation.

On the crestal part, the incisor was still present and multinucleated osteoclasts were prominent on the bone surface. The osteoclast showed intense ACPase activity in its cytoplasm. Mononuclear cells were also observed between osteoclasts and the bone surface. Sinusoidal blood vessels or capillaries were observed close to osteoclasts, and a thin layer of flattened mononuclear cells with a few PAS positive granules was observed between blood vessels and osteoclasts (Fig. 5).

Although osteoclasts were still present in the crestal half of the transitional part near the incisal base, 


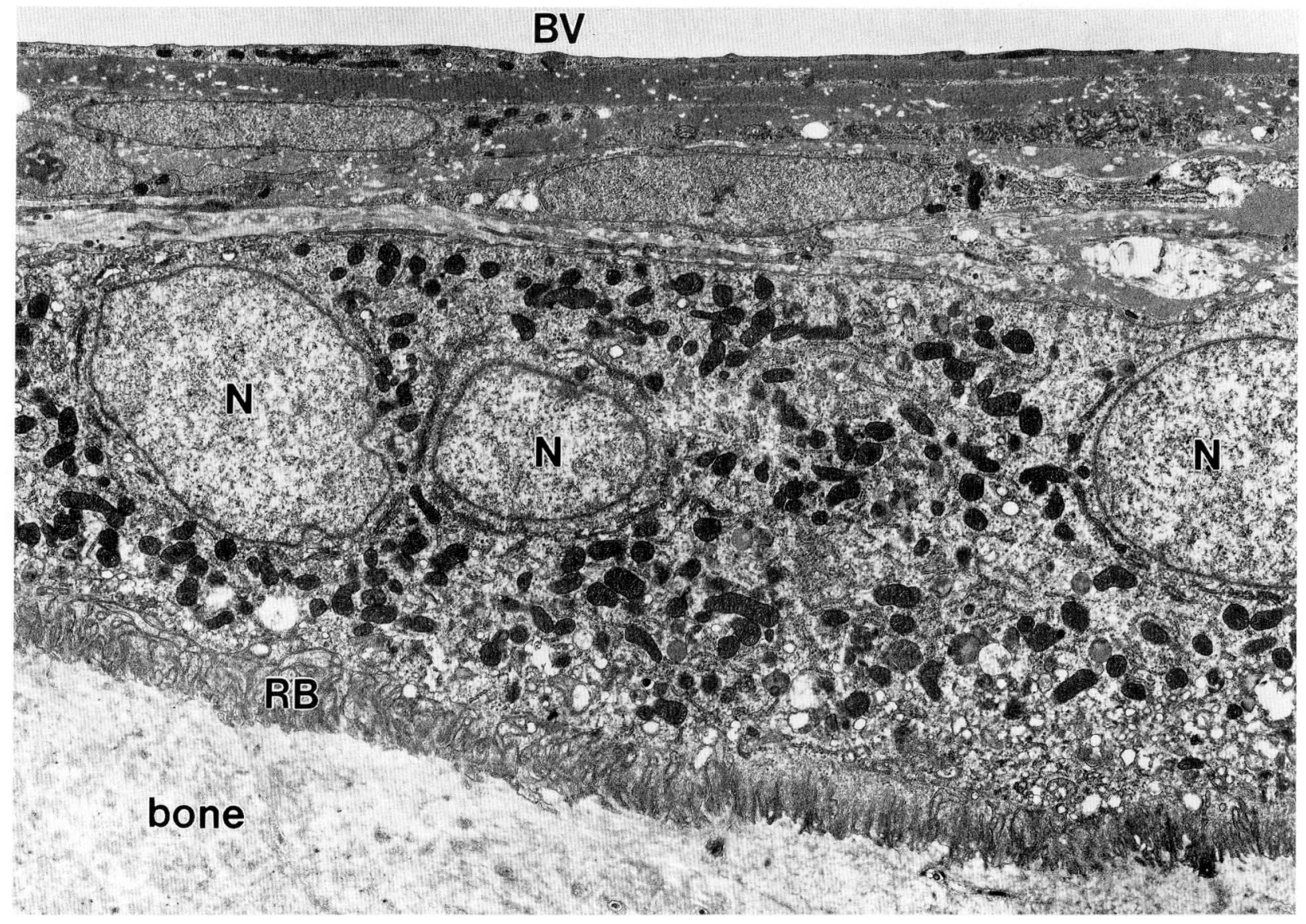

Fig. 10. Multinucleated osteoclasts and flattened cells on the crestal part of bone surface. Note the narrow intercellular space. $B V$ blood vessel, $N$ nucleus, $R B$ ruffled border. $\times 5,500$

both their number and size were reduced. The layers of the mononuclear cells near the bone surface showed stronger PAS positive reactions as reflected by the numerous granules as well. The distance between blood vessels and osteoclasts at the transitional area increased, due to a larger volume being occupied by an intercellular matrix around the flattened cells (Fig. 6). At the basal half of the transitional part, increasing numbers of mononuclear cells were observed on the bone surface. Multinucleated cells with intense ACPase activities were occasionally seen apart from the bone surface (Fig. 7).

Osteoblasts lined up on the bone surface facing the vacant socket located in the basal part. New bone was formed on the cement line. Between osteoblasts and blood vessels, layers of osteogenic cells with PAS positive granules were thickened, while osteoclasts were no longer observed. Some of the cement line showed ACPase activity (Fig. 8).

On the crestal part, ALPase activity was low but detectable near the bone surface, which corresponded to the mononuclear cell layer between the bone surface and blood vessels. This activity increased in the transitional part. On the basal part, the intense activity of ALPase which was detected corresponded to osteoblasts lining up on the bone surface (Fig. 9).

\section{Electron microscopic observations}

On the crestal part, osteoclasts showed typical fine structural characteristics, such as multinucleation, a ruffled border, numerous mitochondria and vacuoles. Flattened mononuclear cells were located close to osteoclasts. Intercellular matrices were scarce (Fig. 10).

On the transitional part, few osteoclasts showed developed ruffled border. Osteoblastic cells or their processes often wedged in between osteoclasts and the bone surface (Figs. 11, 12). Intercellular matrices were enriched. 


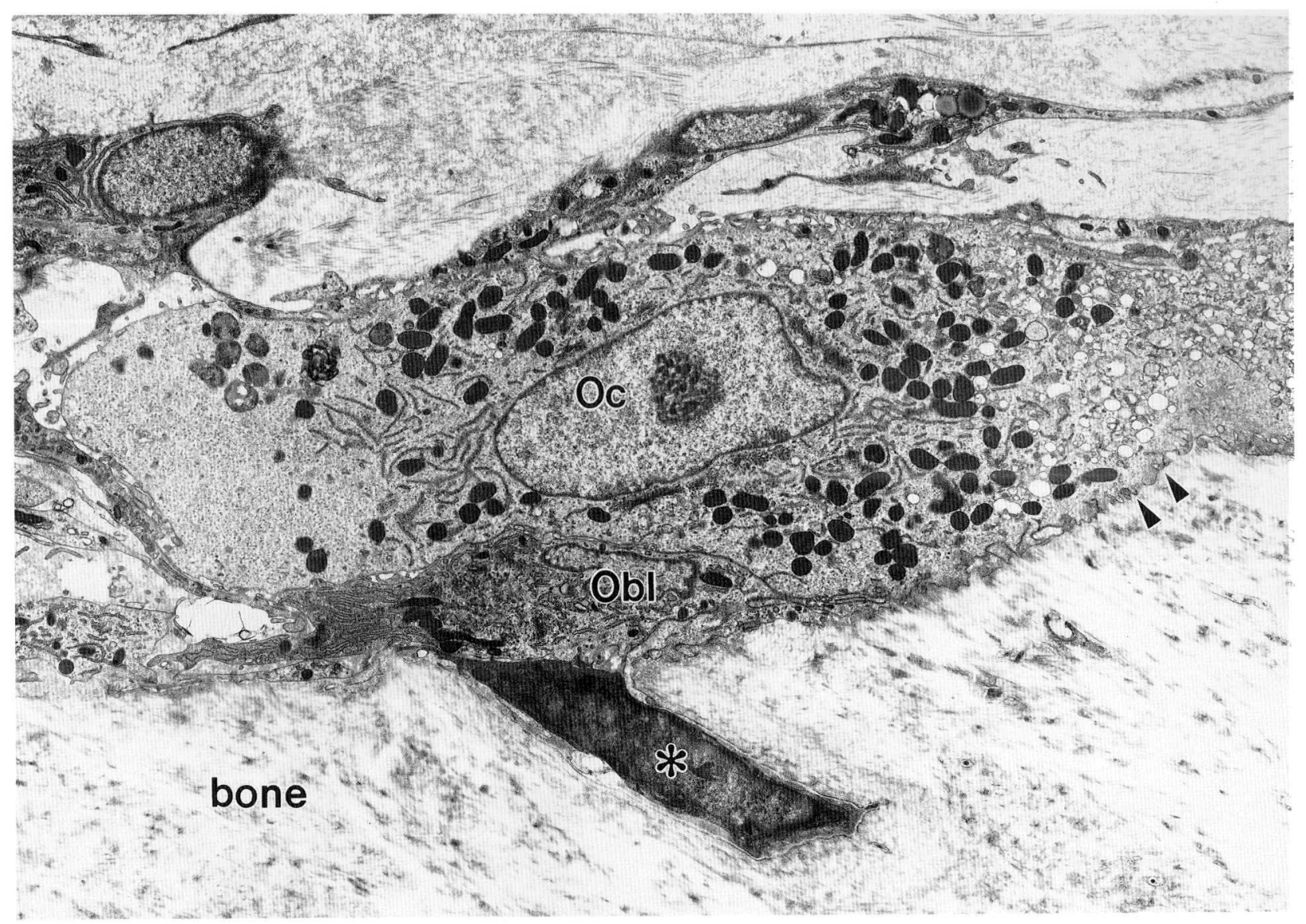

Fig. 11. Osteoblastic cell $(O b l)$ wedged in between an osteoclast $(O c)$ and the bone surface on the transitional part. Reduced ruffled border (arrowheads) suggests the low activity of the osteoclast. Partially released osteocyte (*). $\times 5,000$

On the basal part, osteoblasts with a well developed rER and a Golgi apparatus lined up on the newly formed bone. In the osteogenic cell layer, mitosis was often observed (Fig. 13).

\section{DISCUSSION}

Histological observations after root resection have already been reported by BERKOVITZ and his colleagues (BERKovitz and ThOMAs, 1969; BERKOVITZ, 1971; BERKOVITZ and SHORE, 1978; BERKOVITZ et al., 1980) who demonstrated the existence of a vacant socket behind an erupted incisor. We used similar root-resected incisor sockets as a model to observe histological changes in bone remodeling after the elimination of compressive force, since the alveolar bone which constitutes the vacant socket is considered to be free from any mechanical compressive force mediated by the incisor. Furthermore, peridental tissue composed of periodontium in its lingual part and interspaces between the alveolar bone and enamel in the labial part are less damaged by root resection than by extraction (BERKOVITZ, 1971). Our study demonstrated new bone formation on the labial alveolar bone where the socket was vacant. The finding confirms that continuous bone resorption without bone formation on the labial alveolar bone might be due to compressive forces generated by tooth eruption and occlusion. Therefore, the elimination of compressive force by root resection resulted in bone formation. BERKOVITZ (1971) also reported that, in the healing process of the incisor socket after root resection, a vascular-rich connective tissue remained on the labial alveolar bone surface even after a great portion of the socket had been occupied by newly formed bone: they could not observe new bone formation due to the low power and long term 


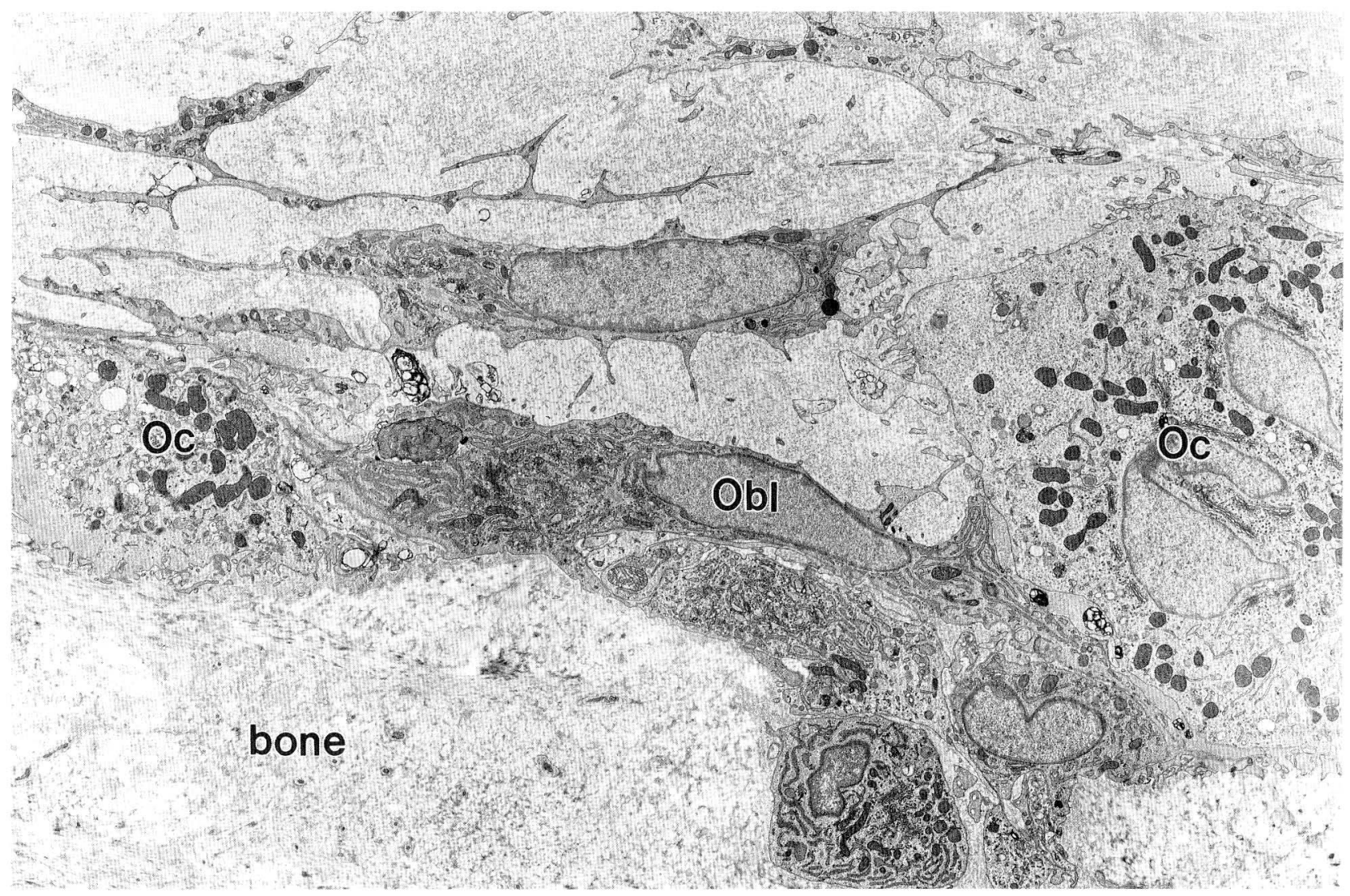

Fig. 12. Osteoblastic cell $(O b l)$ occupying the bone surface between osteoclasts $(O c)$ in the transitional part. $\times 4,000$

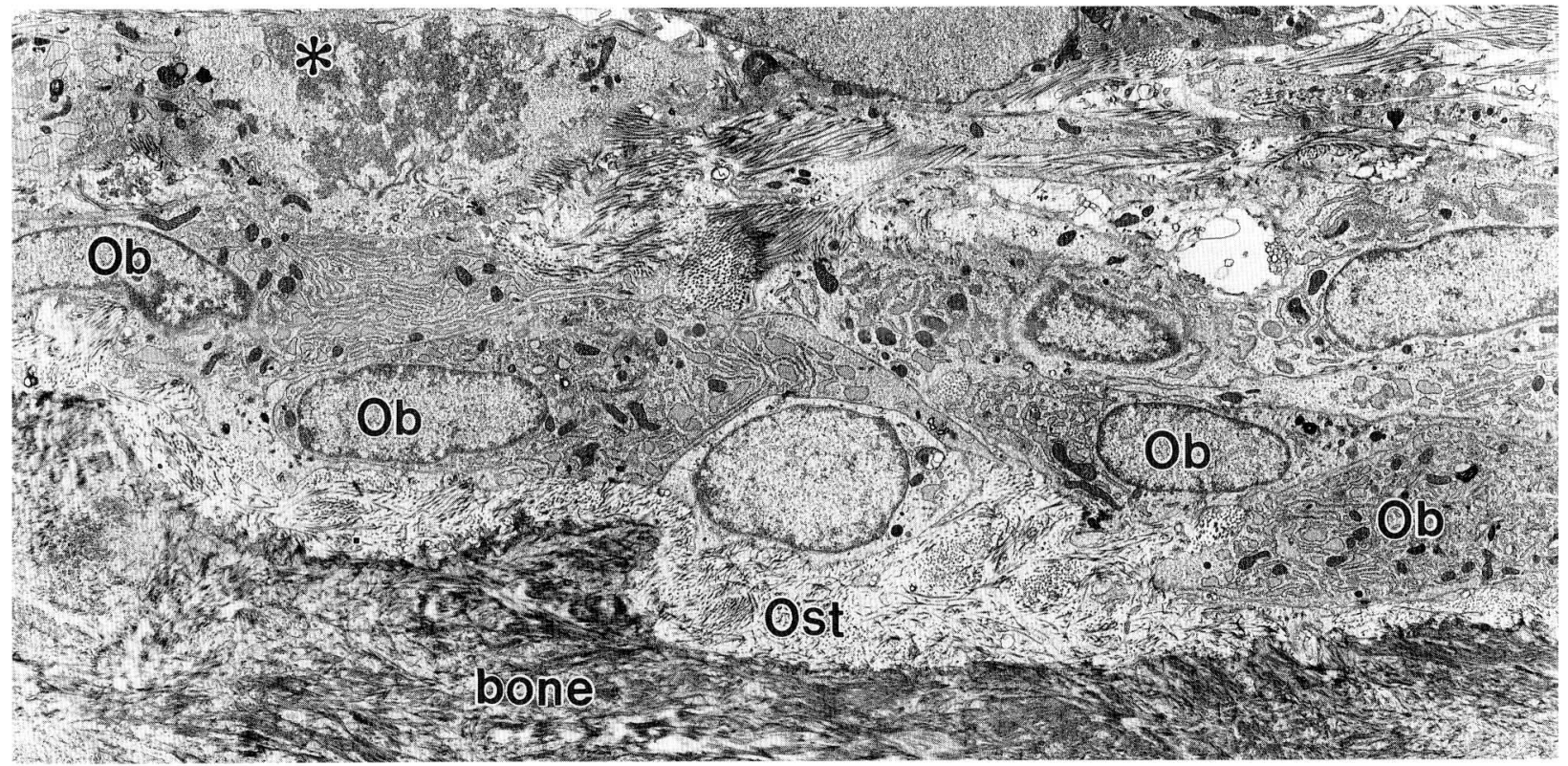

Fig. 13. Osteoblasts $(O b)$ and osteogenic cells with well developed cell organelles on the basal part of the bone surface. Note the newly formed bone (Ost) over the old bone. Mitosis $(*)$ suggests a high activity of osteogenic cells. $\times 4,000$ 
observations carried out in the study.

OzAWA et al. (1989b) recently reported that continuous compressive force inhibits the differentiation of osteoblasts and promotes the formation of osteoclasts. Therefore, on the bone surface after root resection, depressed osteoblastic cells might be activated, and active osteoclasts might be depressed by the elimination of compressive force.

On bone remodeling after root resection, BER KOVITZ et al. (1980) also reported new bone apposition on the lingual alveolar bone. A similar observation has been reported for the hypofunctional molar alveolar bone by TRAN VAN and MAILLAND (1981), wherein they demonstrated that bone remodeling inclines toward bone formation by the extraction of the antagonist. Since the above reports dealt with alveolar bone inserted with Sharpey's fiber, the conversion from bone resorption to bone formation was for them a phenomena difficult to interpret. Contrary to this, we hereby clearly demonstrated the conversion from active bone resorption to bone formation.

In this study, the bone surface of the crestal part was still actively resorbed even after the elimination of occlusal force. The phenomena may be due to the remaining portion of the incisor still pressing in on the bone surface. Nonetheless, the possibility of a developing enamel organ promoting osteoclastic bone resorption cannot be totally denied.

Since the base of the root-resected incisor migrated from its original location following a basal to crestal direction and left a vacant socket behind, with the eruption of the incisor, the conversion of bone resorption to bone formation after elimination of the incisor has first occurred on the basal part, then progressed in a crestal direction. Therefore, the chronological features of bone remodeling were indicated on the bone surface; the crestal part represents the resorption phase, while the basal part indicates the formation phase, and the transitional part could be considered as the reversal phase, as proposed by BARON (1977).

On the transitional part, osteoclasts reduced their activities and disappeared, while the number of mononuclear cells with PAS-positive granules and the number of granules in the cytoplasm increased. Some of the PAS-positive granules may represent lysosomal activities, since the activity was coincident with ACPase activity detected by histochemistry, in addition to glycogen suggesting an osteogenic property for the increasing mononuclear cells in the transitional part. Phagocytic cells were often observed apart from bone surface, however, not on the bone surface as was the case in the report of BARON et al.
(1980). This discrepancy might have arisen from the difference in the density of fibers between the observation sites, i.e., the outer surface of the alveolar bone is much denser in fibers than the enamel portion of the incisor alveolar bone surface; hence, the phagocytic cell population would be more important on the outer surface.

OGURO and OzAWA $(1988,1989)$ demonstrated ACPase activity on eroded bone surface. We observed a low ACPase activity on the transitional bone surface and cement line, which might have been caused by a weakened activation of the enzyme due to a longer decalcification, since sections that underwent longer incubation showed higher ACPase activity.

On the resorption phase or reversal phase, many investigators suggested explanations for the mononuclear cells being located close to osteoclasts or the bone surface: RIFKIN and HEIJL (1979) considered them as "fibroblast-like" cells involved in organic bone matrix degradation after the removal of bone mineral by osteoclasts; KURIHARA and ENLOW (1980) described them as "osteoclast companion cells" with a depository function; while BARON and his colleagues suggested these cells to play a specific role in the coupling mechanism between resorption and formation either by scavenging of the resorbed bone surface or by secreting the organic substance of the cement line on the resorbed bone surface (BARON et al., 1980; TRAN VAN et al., 1982). Furthermore, EJIRI (1983) suggested that preosteoblasts have an influence on the differentiation of osteoclasts.

In this study, flattened cells were located behind and close to active osteoclasts in the crestal part. On the transitional part, osteoblastic cells or their processes were often located between inactive osteoclasts and the bone surface. Mononuclear cells were appearently active between osteoclasts and blood vessels, and increased the thickness of the layer by enriching the intercellular matrix or collagen fibers. BERKOVITZ and SHORE (1978) reported active fibroblastic cells at the transitional part. These findings suggest two possibilities for these mononuclear cells to participate in the inactivation of osteoclasts; either by direct effect on the osteoclasts, or by indirect effect controlling the access of blood vessels to the bone surface. The latter is plausible since blood vessels may control local oxygen tension, nutritional supply and elimination of waste matters. Moreover, they seem to serve as pathways for osteoclastic progenitor supply. Furthermore, GOLDHABER (1963) suggested that high oxygen tension stimulates both the formation and resorption of bone, whereas lower oxygen tensions only stimulate formation. 
Inactivathon of activated osteoclasts after the elimination of the incisor may partially be due to a reduction of prostaglandins, since mechanical forces stimulate the synthesis and release of prostaglandins (PGs) in bone tissue (HARELL et al., 1977; SOMJEN et al., 1980), and PGs in turn promote the formation of osteoclasts (AKATSU et al., 1989).

In conclusion, the results demonstrate that the elimination of compressive force mediated by the incisor leads to the activation of osteogenic cells and inactivation of osteoclasts, resulting in a conversion from bone resorption to bone formation on the alveolar bone facing the enamel. These findings suggest that osteogenic cells may play an important role in controlling osteoclastic activity in conversion from bone resorption to bone formation.

Acknowledgments. We thank Associate Prof. S. EJIRI, Department of Oral Anatomy, Niigata University School of Dentistry, for continuous support and advice; and the staff of the Department of Oral Anatomy for their assistance.

\section{REFERENCES}

Akatsu, T., N. Takahashi, K. Debari, I. Morita, S. Murota, N. Nagata, O. Takatani and T. Suda: Prostaglandins promote osteoclastlike cell formation by a mechanism involving cyclic adenosine 3',5'-monophosphate in mouse bone marrow cell cultures. J. Bone Mineral Res. 4: 29-35 (1989).

AzUma, M.: Study on histologic changes of periodontal membrane incident to experimental tooth movement. Bull. Tokyo Med. Dent. Univ. 17: 149-178 (1970).

BARON, R.: Importance of the intermediate phases between resorption and formation in the measurement and understanding of the bone remodeling sequence. In: (ed. by) P. J. MEUnier: Bone histomorphometry. Lab. Armour Montagu, Paris, 1977 (p. 179-183).

Baron, R., A. Vignery and P. Tran Van: The significance of lacunar erosion without osteoclasts: Studies on the reversal phase of the remodeling sequence. Metab. Bone Dis. Rel. Res. 2S: 35-40 (1980).

Berkovitz, B. K. B.: The healing process in the incisor tooth socket of the rat following root resection and exfoliation. Arch. Oral Biol. 16: 1045-1054 (1971).

Berkovitz, B. K. B. and R. C. Shore: The ultrastructure of the enamel aspect of the rat incisor periodontium in normal and root-resected teeth. Arch. Oral Biol. 23: 681-689 (1978).

Berkovitz, B. K. B. and N. R. Thomas: Unimpeded eruption in the root-resected lower incisor of the rat with a preliminary note on root transection. Arch. Oral Biol. 14: 771-780 (1969).

Berkovitz, B. K. B., R. C. Shore and P. Sloan: His- tology of the periodontal ligament of rat mandibular incisor following root resection, with special reference to the zone of shear. Arch. Oral Biol. 25: 235-244 (1980).

Burger, E. H., J. W. M. VAn Der Meer and P. J. NiJWEIDE: Osteoclast formation from mononuclear phagocytes: Role of bone-forming cells. J. Cell Biol. 99: 1901-1906 (1984).

Burstone, M. S.: Histochemical demonstration of acid phosphatases with naphthol AS-phosphates. J. Nat. Cancer Inst. 21: 523-539 (1958).

- : Alkaline phosphatase, naphthol AS phosphate method. In: (ed. by) M. S. Burstone: Enzyme histochemistry and its application on the study of neoplasms. Academic Press, New York, 1962 (p. 275-276).

EJIRI, S.: The preosteoclast and its cytodifferentiation into the osteoclast: Ultrastructural and histochemical studies of rat fetal parietal bone. Arch. Histol. Jap. 46: 533-557 (1983).

Goldhaber, P.: The influence of oxygen tension and embryo extract on bone remodeling in tissue culture. J. Cell Biol. 19: 27A-28A (1963).

Harell, A., S. Denkel and I. Binderman: Biochemical effect of mechanical stress on cultured bone cells. Calcif. Tiss. Res. Suppl. 22: 202-209 (1977).

IRIE, K. and H. OzAWA: Relationships between tooth eruption, occlusion and alveolar bone resorption: Cytological and cytochemical studies of bone resorption on rat incisor alveolar bone facing the enamel. Arch. Histol. Cytol. 53: 497-509 (1990).

KURIHARA, S.: An electron microscopic observation on cells found in bone resorption area incident to experimental tooth movement. Bull. Tokyo Med. Dent. Univ. 24: 103-123 (1977).

Kurihara, S. and D. H. Enlow: A histochemical and electron microscopic study of an adhesive type of collagen attachment on resorptive surfaces of alveolar bone. Amer. J. Orthod. 77: 532-546 (1980).

McManus, J. F. A.: Histological and histochemical uses of periodic acid. Stain Tochnol. 23: 99-108 (1948).

OGURo, I. and H. Ozawa: The histochemical localization of acid phosphatase activity in BMU. J. Bone Mineral Metab. 6: 190-195 (1988).

- Cytochemical studies of the cellular events sequence in bone remodeling: Cytological evidence for a coupling mechanism. J. Bone Mineral Metab. 7: 30-36 (1989).

Okada, M. and T. Mimura: Zur Physiologie und Pharmakologie der Hartgewebe. I. Mitteilung: Eine Vitalfärbungsmethode mit Beisalzen und ihre Anwendung bei den Untersuchungen über die rhythmische Streifenbildung der harten Zahngewebe. Jap. J. Med. Sci. Pharmacol. 11: 166-170 (1938).

Ozawa, H., S. EjIRI, I. Oguro, M. Ikegame, K. Irie, H. Nakamura, T. Iwasaki, T. Mohri and K. Yamada: Cellular events involved in bone remodeling Mechanocytological studies. In: (ed. by) K. KuBota: Mechanobiological research on the masticatory system. Tokyo Press, Tokyo, 1989a (p. 177-182). 
Ozawa, H., K. Imamura, T. Fukuhara, Y. Shibasaki, N. Takahashi, E. AbE and T. Suda: Effects of continuously applied compressive force on bone formation and resorption in vitro. In: (ed. by) K. KuBota: Mechanobiological research on the masticatory system. Tokyo Press, Tokyo, 1989b (p. 188-193).

Rifkin, B. R. and L. HeIJL: The occurrence of mononuclear cells at sites of osteoclastic bone resorption in experimental periodontitis. J. Periodontol. 50: 636-640 (1979).

RYGH, P.: Ultrastructural cellular reactions in pressure zones of rat molar periodontium incident to orthodontic tooth movement. Acta Odont. Scand. 30: 575-593 (1972).

: Ultrastructural changes in pressure zones of human periodontium incident to orthodontic tooth movement. Acta Odont. Scand. 31: 109-122 (1973).

Schwarz, A. M.: Tissue changes incidental to orthodontic tooth movement. Amer. J. Orthod. 18: 331-352 (1932).

Somjen, D., I. Binderman, E. Berger and A. Harell: Bone remodelling induced by physical stress is prostaglandin $\mathrm{E}_{2}$ mediated. Biochim. Biophys. Acta 627: 91100 (1980).

Takahashi, N., T. Akatsu, N. Udagawa, T. Sasaki, A. Yamaguchi, J. M. Moseley, T. J. Martin and T. SuDA: Osteoblastic cells are involved in osteoclast formation. Endocrinology 123: 2600-2602 (1988).
Tran Van, P. and M. L. Mailland: Short-term effects of occlusal hypofunction following antagonist tooth extraction upon periodontal tissues in the rat. J. Biol. Buccale 9: 385-400 (1981).

Tran Van, P., A. Vignery and R. Baron: An electronmicroscopic study of the bone-remodeling sequence in the rat. Cell Tiss. Res. 225: 283-292 (1982).

ZaKı, A. E. and G. VAN HuYsen: Histology of the periodontium following tooth movement. J. Dent. Res. 42: 1373-1379 (1963).

Dr. Kazuharu IRIE

Department of Oral Anatomy

Niigata University School of Dentistry

Gakkocho-dori 2

Niigata, 951 Japan

入 江 一 元

951 新潟市学校町通 2

新潟大学歯学部

口腔解剖学第一教室 